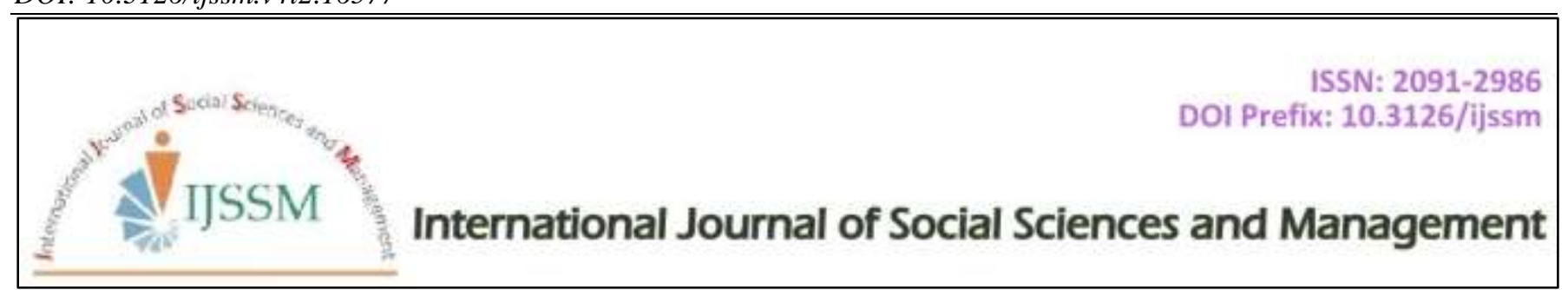

Case study

\title{
An Evaluation of the Effects of Motivation, Satisfaction on Destination Loyalty: Case Study Tourism Malaysia
}

\section{Md Shafiin Shukor*, Norlida Hanim Mohd Salleh and Siti Hajar Mohd Idris}

School of Economics, Faculty of Economics and Management, Universiti Kebangsaan Malaysia, 43600 UKM Bangi, Selangor, Malaysia.

*Corresponding author's email: ikhwan_6101@yahoo.com

\begin{abstract}
In tourism literature, stimulation of motivation on tourist journey is one of the vital aspect. This study analyzed the satisfaction and loyalty based on a sample of 200 respondents from four regions, namely Southeast Asia, West Asia, Europe and America. The selection of four regions was due to several reasons which are, i) market for Southeast Asia is the leading supplier of arrivals, ii) Western Asian markets showed an increase in the arrival of the high impact of the September 11th incident, iii) European and American Markets were to represent the market of developed countries. This study, based on the method of Strutural Equatation Model (SEM) using Statistical Package for Social Science version (SPSS 21.0) and Analysis of Moment Structures 5 (AMOS 5) as a tool of analysis. SEM methods used to test the analysis of cause, and effect variables are independent and dependent variables as well as specific information to estimate the structural equation model based on variance value. It was used to test Exploratory Factor Analysis (EFA) and AMOS 5 used to test Confirmatory Factor Analysis (CFA). Results of this study found that the assessment made by foreign visitors to the Malaysia tourism products and services is positive. As a result, the experience will create loyalty to Malaysia's tourism industry in the form of repeat visits $(\beta: 0.547$, ttest: $7.472 * * *)$ and promote the destination to friends and relatives that have the potential to make visits $(\beta$ : 0.794 , the t-test: $8.623 * * *)$. However, it was found that the value of the coefficient of regression for stimulus push is low for satisfaction ( $\beta$ : 0.228 , t-test: $1.976 * *)$. This findings could be used as guidance to the authorities and operators, policy makers in knowing real satisfaction that stimulates tourist arrivals to Malaysia.
\end{abstract}

Keyword: Motivation; Satisfaction; Loyalty; Tourism, Economy

\section{Introduction}

The tourism sector plays an important role in enhancing the economic growth of a country. The sector is also one of the main source of national income and the local community. This causes the nation to highly depend on the tourism industry such as Malaysia for instance.

Malaysia has lifted the tourism sector as a key economic areas in Malaysia Plan (2006-2010). During that period, the income of tourism industry increased by 67.1 percent to 53.4 billion and tourist arrivals increased by 43.6 percent to 23.6 million people ( $10^{\text {th }}$ Malaysia Plan Report).

During the period of the tenth Malaysia Plan (2011-2015), the Government was targeting to increase the tourism industry to a higher level through the transformation plan for Tourism Malaysia, that "2020:36:168" which is 36 million tourists with a total of RM168 billion in 2020. While Economic Tranfomation Program (ETP) on the other hand there are 12 projects divided into five (5) themes that want to be focus which are affordable luxury, nature hikes, family entertainment, events, entertainment, spa and sports and tourism business. Through the strategy, Malaysia expects the revenue from tourism reached RM103.6 million by 2020. Even though, there are change in the target achieve but if the destination country is not able to provide products and services that give satisfaction to tourists, it will not increase the influx of tourists to Malaysia.

Therefore, it is necessary to understand the needs and requirements of travelers vary because each visitor experience assessment based on desire before they decide 
to travel. Assessment made based on experience either in the form of positive or negative. If the tourist experience is positive towards the products and services offered, then it creates loyalty in the form of repeat visits and promote the destination to friends and relatives that have the potential to make a visit. For potential visitors, the sources of information are important and very reliable.

Meanwhile, products and services in tourism is in the form of homogeneous, then it is necessary to understand the needs and satisfaction of tourists because that matter is an important variable in marketing. Hence, the satisfaction rating information is vital to a particular any marketing and management.

Hopefully, the results from this study can become the foundation in increasing the satisfaction and overcoming the weakness in order to increase the arrival of tourist to Malaysia. The organization structure of this study inclusive with the discussion of theoretical model and literature reviews, methodology, findings and discussion together with conclusion and policy implication.

\section{Theoretical Model and Literature Review}

The motivation of tourists is essential to be understood and to forecast the future travel patterns (Khuong and Ha, 2014). This motivation will show that travelers have chosen and traveled for some reason. As usual, someone will go traveling based on the concept of push and pull factors (Crompton, 1979). This concept is fundamental to know the dimensions and the type of person to go traveling to tourist destination of choice. So the concept has become the framework in this study because the push and pull factors can contribute to tourism replication (Khuong and Ha, 2014).

\section{Push Factors}

Push factors are factors that contribute to a person's need to feel out of place of origin (Crompton, 1979). This means someone away to look for something different, away from the daily routine, escape from work and something similar (Dowell, 2011). In other words, the push factors related to the emotional aspects of a person (Lam and Hsu, 2006). Normally, this factor exists from their experience at work or busy big city life as they did not have time to rest after years of working (Yiamjanya and Wongleedee, 2014). So, they feel the need to find peace away from daily routine to find places suitable for relaxation (Baniya and Paudel, 2016; Pesonen, 2012) in which the place can refresh the mind to go back to work (Pesonen, 2012). Ultimately, someone who takes the time to relax outside area will enhance the ability of themself because they have a new experience and something different from their locality (Yoon and Uysal, 2005).

In addition, someone is out of home to enjoy the new area will definitely faces the challenges (Uysal, McGehee and
Loker-Murphy, 1996). This is because, it will be outside of their locality that certainly has different in term of culture, language, social and environmental as different as West Asia to Southeast Asia. This is a challenge for those who like to measure the ability of ourselves as adventurers who have different backgrounds (Reihanian et al., 2015).

\section{Pull Factors}

Pull factors are related to the attractiveness of a location in a tourist destination. However, before they decide to travel to a place where some considerations of cost, convenience, distance and travel time, security and transport will be done. Studies by Reihanian et al., (2015) in Iran shows that the reachability on location is an important element in determining the tourist destination. This is because it it involved costs, facilities, distance and travel time.

The attraction is also related to the characteristics of destinations such as natural scenery (marine parks, nature reserves, beaches, mountains, waterfalls) facilities and infrastructure in places of recreation (Baniya and Paudel, 2016; Pesonen, 2012), food (Yiamjanya and Wongleedee, 2014), culture (Uysal, McGehee and Loker-Murphy, 1996), entertainment and shopping (Yoon and Uysal, 2005). Studies by Pesonen (2012) in Taipei shows that the factor of natural resources as one of the most important to encourage tourists to come back. A study by Yiamjanya and Wongleedee (2014) in Thailand showed that traditional Thai food appears as a leading tourist attraction in Thailand.

Satisfaction and loyalty studies have been noticed in past years. Previous researchers use a variety of theories to understand the attitudes, the behavior of tourists to assess the level of satisfaction and loyalty of tourists at a tourist destination. According to the Theory of Reasoned Action (TRA) (Fishbein and Ajzen, 1977) which states that every behavior driven by particular reasons. This means, the formation of behavior involves an interaction between an individual's belief systems with consideration or evaluation of various aspects of this reaction will form the reasons that drive the behavior.

\section{Tourist Satisfaction}

Undoubtedly, the aspects of a product and service satisfaction are so important to consumers. For consumers, the product or service must offer something different because it is able to distinguish itself and give satisfaction to the consumer and to maintain the demand for the products and services (Valle et al., 2006).

For travel products and services, evaluation of customer satisfaction made by tourists after they use the products and services (Tse and Wilton, 1988) and the assessment made in the hope of being able to meet expectations or exceed expectations (Williams and Soutar, 2009). For tourist destinations which are not able to provide products and 
services to cater the needs of tourists at certain times then it can give rise to discontent with tourism product or services.

Therefore, some aspects need to be considered in designing the study on the level of satisfaction of tourists. Satisfaction of tourism can be divided into two parts, namely, push and pull. The push is assessing the needs of satisfaction and tourist demand. This is because tourists who set goals, types of tourism and travel needs in the respective destination (Ryan, 1995).

While the satisfaction of the pull factors are based on a tourism destination. This assessment involves factors such as cleanliness of the destination, the destination or country's image, readiness and product diversification in tourism and infrastructure to support the quality of service offered. The basic dimensions of the image of tourist destinations that used in the study of previous authors such as journey environment, the safety, the local attractions, facilities, infrastructure, aspects of relaxation, outdoor activities as well as price and cost of travel (Salleh et al., 2011; Couto et al., 2011; Shuaib et al., 1989; Thongma et al., 2011).

Safety is a necessity in the life of a human being. Security requirements include individual wants to be free from the danger of body and soul, free from intimidation, and free from the threat. In the tourism sector security is a factor that is considered by tourists because if tourists feel safe, it will lead to the satisfaction of the tourist destination (Salleh et al., 2013).

In addition, the rapid and efficient management offered by tourism operators are able to give satisfaction to tourists (Couto et al., 2011). Tourism operators should establish a high level of satisfaction to tourists in order to improve and maintain the competitiveness of the tourist destinations (Yoon and Uysal, 2005).

There are, no doubt the arrival of more tourists to a tourist destination will increase prices because demand exceeds supply. However, if the per capita income is higher than the price of tourist offer and tourist feel the price is still reasonable from the point of origin, they feel something should be done and they will make a trip to the destination (Salleh et al., 2011).

\section{Tourist Loyalty}

The use of occurrences or propose to people who potentially are usually referred to as the user loyalty marketing (O'Malley, 1998). Similarly, travel products and services can be considered as products that can be reused or recommending travel destinations to potential tourists such as friends or relatives.

Loyalty is considered as one of the prime power mover in the market competition (Havitz, Dimanche and Bogle,
1994). The successful marketing strategies will be able to attract customers to use the products or services offered there by sustain loyalty by a long-time user and increase usage by new users (Kotler and Keller, 2009). Similarly, if a destination provides travel products and services that can provide satisfaction to our customers, it is able to maintain fidelity, then certain tourists who have already experience the journey shows a positive attitude towards the destination, thus affecting the tourism potential.

According Gremler and Brown (1996) customer loyalty is also seen as a level that reflects the purchase of a product and service repeatedly from manufacturers of products and services and have a positive attitude towards manufacturers of products and services. Oliver (1997), defines customer loyalty as existing commitments to repurchase a product or service that is favored in a row in the future, despite the influence of the environment and potential business used to change the behavior of customers to other items.

The concept and the level of loyalty is one of the critical indicators that are used directly to measure the success of marketing strategies (Flavian, Martinez and Polo, 2001). According Gremler and Brown (1999), customer loyalty is that the customers are more likely to spread positive word of mouth and purchase products and additional services. Hence it is important because customers believe in your products and services and do not tend to look for other alternatives unsatisfaction.

Therefore, the framework and research hypothesis are as follows:

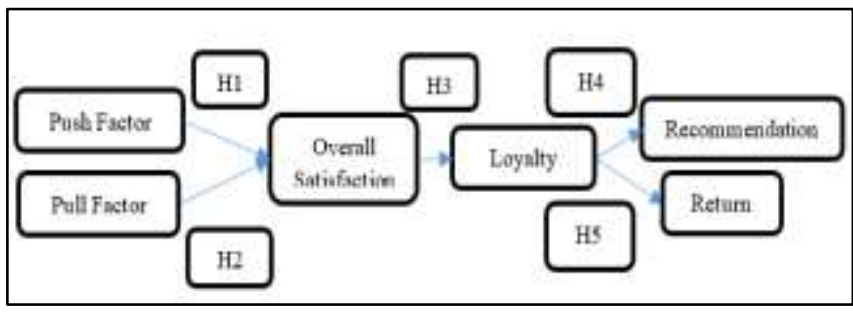

Fig. 1: Research Model

Hipotesis 1 (H1): There is direct relationship between Push factor value and overall saticfaction.

Hipotesis 1 (H2): There is direct relationship between Pull factor value and overall saticfaction.

Hipotesis $1(\mathrm{H} 3)$ : There is direct relationship between overall satifaction and loyalty.

Hipotesis 1 (H4): There is direct affect between loyalty and recommed.

Hipotesis 1 (H5): There is direct affect between loyalty and return. 


\section{Methodology}

Discussion on methodology is divided into several parts which are sampling and analysis, and analysis of the survey instrument.

\section{Sampling Locations and Review}

The respondents comprised of four areas of Southeast Asia, West Asia, Europe and America. The selection of four (4) areas because the area is the busiest tourist arrivals and continues to increase each year (Table 1).

This study used primary data collection which is distributed to 200 people tourists visiting Malaysia. Respondents were interviewed together and each group of more than 3 but not more than 6 people. This is because, the majority of respondents came to Malaysia in groups. Thus, each group was given a questionnaire to give their assessment. Demographic information collected from each group leader. The sample survey respondents to represent the population under study is done randomly. The amount of each substrate is carried out with equal distribution. This amount is determined based on the justification that this amount be sufficient to represent the population of tourists who visit Malaysia. In this way the respondents are more thoroughly to assess tourist satisfaction. Location enlightenment questionnaires area around Kuala Lumpur Low Cost Carrier Terminal (LCCT) and the Kuala Lumpur International Airport (KLIA) which has been identified as tourist spots.
This location was chosen because respondents have tasted and enjoyed the Malaysian tourism products and services.

\section{Research Instrument}

This questionnaire uses English and the questionnaire consists of five sections. The first part is related to demographic travelers. Question is closed and there are seven questions related to respondent's profile.

Part two (2) is on push factor consisting of 12 variables items. This section evaluates the level of importance of each item variables. Part three (3) contains the image of a destination that consists of 25 items of variables. This section examines the level of satisfaction of each item variables. All parts 2 and 3 of the questionnaire using a five point scale from 1 "Very Unimportant" to 5 "Very Important".

Part four (4) includes the satisfaction of "Malaysia has exceeded my expectations in advance", "I am very satisfied with my trip in Malaysia" and "Malaysia offers the best value for money". Each of the items are using the scale of five, namely namely 1 "Extremely Dissatisfied". While the top five (5) regarding the level of satisfaction regarding "repeat traveling" and "suggest to friends and relatives." Both items using a scale of five from "Strongly agree" to 5 "strongly agree".

Table 1: Statistics of Tourists

\begin{tabular}{llllll}
\hline Year & Southeast Asia & West Asia & Americas & Europe & Africa \\
\hline 2000 & 136,641 & 38,904 & 239,899 & 527,929 & 11,540 \\
2001 & 158,528 & 60,111 & 184,762 & 545,758 & 20,766 \\
2002 & 192,774 & 65,173 & 162,916 & 531,793 & 13,720 \\
2003 & 155,565 & 31,315 & 158,049 & 363,137 & 12,577 \\
2004 & 184,202 & 66,720 & 177,916 & 435,382 & 16,511 \\
2005 & 238,098 & 89,961 & 182,521 & 505,440 & 16,381 \\
2006 & 297,799 & 110,451 & 209,066 & 562,711 & 20,174 \\
2007 & 449,667 & 126,048 & 251,747 & 686,938 & 21,233 \\
2008 & 613,867 & 117,778 & 300,913 & 879,529 & 25,437 \\
2009 & 691,502 & 107,455 & 316,651 & 988,317 & 23,556 \\
2010 & 807,101 & 121,565 & 324,666 & $1,013,018$ & 26,395 \\
2011 & 838,673 & 120,482 & 302,770 & 975,113 & 31,441 \\
2012 & $1,171,123$ & 184,749 & 328,644 & $1,029,895$ & 48,660 \\
2013 & $1,141,564$ & 194,368 & 338,125 & $1,074,379$ & 51,953 \\
2014 & $1,364,748$ & 223,180 & 356,923 & $1,202,429$ & 51,951 \\
2015 & $1,147,967$ & 183,656 & 325,593 & $1,078,953$ & 47,382 \\
\hline
\end{tabular}

Source: Tourism Malaysia (tourism.gov.my/statistics) 


\section{Research Analysis}

This study used Strutural Equatation Model (SEM) using Statistical Package for Social Science version (SPSS 21.0) and Analysis of Moment Structures 5 (AMOS 5) as a tool of analysis. SEM methods used to test the analysis of cause and effect on independent and dependent variables as well as to estimate the SEM based on the value of variant. SPSS was used to test Exploratory Factor Analysis (EFA) and AMOS 5 used to test Confirmatory Factor Analysis (CFA). The test of EFA is to form clusters of factors and test CFA was to assess the validity of the model structure.

EFA test is conducted to arrange groups of factors that have a value equal weight. Once grouped, the group may be named dimensions corresponding to item variables. It aims to identify any dimension that has the highest or lowest mean.

Test on Exploratory Factor Analysis (EFA) was carried out to test the validity of each variable to form several clusters of factors by using Statistical Package for Social Science (SPSS 21.0). The Test for validity is Kaiser-Meyer-Olkin (KMO) and Bartlett's Test of Sphericity, varimax rotation, total variance explanined, mean score and reliability test (Reliability Test-Cronbach's Alpha).

Kaiser-Meyer-Olkin (KMO) test is to know the data is analyzed in respect of the terms of the distribution of values. Value received in adequate condition more than 0.5. Bartlett's Test of Sphericity (P) to determine the colleration of matrix is the identity matrix and the value received is $p$ less than 0.001. Varimax rotation is used in EFA as a form of batch and benchmarks to the item variable load. For benchmarking cluster Factor of 1.0 and above and item variables load 0.4 above is used as a benchmark. Factors Cluster and load variables will be deleted indicating batch factor and low load $(<0.10)$ and $(<0.40)$.

Total variance test is explained to see batch percentage factor of the study. This factor shows the percentage of the overall interest of all batches examined and knowing how big the factor could explain the original cluster variable. Percentage value contributing to the variance is sufficient for more than 5 percent. The value of the mean score is used to explain the mean level of satisfaction and loyalty of the respondent to determine the level of satisfaction and loyalty of these variable questions posed. For the scale of five points, the mean scale under 2.5 considered insignificant while Scale Mean 2.5 and above is considered important (Salleh et al., 2011). Test Reliability (Reliability TestCronbach's Alpha) is to assume that each item is considered to be an equivalent test and all correlation between the items measured are the same. Cronbach Alpha's value received sufficient more than 0.6 and item variables must be sufficient for more than 3 .

While test on Confirmatory Factor Analysis (CFA) or Measurement Model (MA) with structural equation modeling (SEM) apply equation models using software Analysis of Moment Structures 5 (AMOS 5). Measurement model through confirmatory factor analysis is using the criteria for goodness of fit (GOF) by looking at the index value of the Chisquare and Probability Level (P), CMIN/DF (The Minimum Sample Discrepancy Function/Degree Of Freedom) GFI (Goodness of fit index), RMSR (Root Mean Square Residual), RMSEA (Root Mean Square Error Of Approximation), AGFI (Adjusted Goodness-Of-Fit), NNFI (Nonnormed Fit Index), PNFI (Parsimonious Normed Fit Index), CFI (Comparative fit index), IFI (Incremental Fit Index) and RFI (Relative Fit Index) according to previous research.

Estimate Maximum Likelihood (ML) is the method of SEM which examine to validate the instrument. This followed by path analysis to examine the relationship between variables in the structural model. ML methods is to see the critical ratio (C.R) obtained from the estimator divided by the standard error (S.E). The higher the value, the more significant C.R. If the sample is large, then the C.R outside the \pm 1.96 will generate significant value estimator at the level of 5 percent, while if above 2.56 is significant at 1 percent level.

\section{Findings}

Discussion on the results is divided into several sections, namely, the respondent's demographic, Exploratory Factor Analysis (EFA), Confirmatory Factor Analysis (CFA) and The assessment of the structural model.

\section{Demographics of Respondents}

In this study, a total of 200 respondents were answering questions through questionnaires. Based on table 2, there are differences between the gender visiting Malaysia. A total of 63.0 per cent of tourists comprising men and 37.0 percent of female travelers. In terms of marital status, 103 tourists has not been married or single, 87 people married, while 10 tourists who have divorced. Most tourists aged between 21-30 years (40.0 percent).

Followed by 28.0 percent consists of those who aged between 31-40 years. While for travelers aged 41-50 amounted to 19 percent. Travellers aged under 15 years and 51-60 years amounted to 7.0 percent. 
Table 2: Demographics of Respondents

\begin{tabular}{|c|c|c|c|c|c|c|}
\hline Information & $\begin{array}{c}\text { Southeast } \\
\text { Asia }\end{array}$ & $\begin{array}{l}\text { West } \\
\text { Asia }\end{array}$ & Europe & Americas & Total & Percentages \\
\hline \multicolumn{7}{|l|}{ Gender: } \\
\hline Male & 31 & 39 & 24 & 32 & 126 & 63.0 \\
\hline Female & 19 & 11 & 26 & 18 & 74 & 37.0 \\
\hline \multicolumn{7}{|l|}{ Marital Status: } \\
\hline Single & 23 & 26 & 29 & 25 & 103 & 51.5 \\
\hline Married & 22 & 24 & 18 & 23 & 87 & 43.5 \\
\hline Divorced & 5 & 0 & 3 & 2 & 10 & 5.0 \\
\hline \multicolumn{7}{|l|}{ Age: } \\
\hline Below 15 & 0 & 0 & 0 & 0 & 0 & 0 \\
\hline $16-20$ & 1 & 4 & 6 & 3 & 14 & 7.0 \\
\hline $21-30$ & 21 & 20 & 25 & 14 & 80 & 40.0 \\
\hline $31-40$ & 14 & 14 & 9 & 19 & 56 & 28.0 \\
\hline $41-50$ & 10 & 10 & 7 & 9 & 36 & 18.0 \\
\hline $51-60$ & 4 & 2 & 3 & 5 & 14 & 7.0 \\
\hline 61 and above & 0 & 0 & 0 & 0 & 0 & 0 \\
\hline \multicolumn{7}{|l|}{ Education Level: } \\
\hline Below Degree & 13 & 10 & 6 & 4 & 33 & 16.5 \\
\hline Degree & 34 & 33 & 25 & 39 & 141 & 70.5 \\
\hline Master & 3 & 7 & 7 & 6 & 23 & 11.5 \\
\hline $\mathrm{PhD}$ & 0 & 0 & 2 & 1 & 3 & 1.5 \\
\hline \multicolumn{7}{|l|}{ Employment: } \\
\hline Profesional & 40 & 23 & 35 & 36 & 134 & 67.0 \\
\hline Non profesional & 7 & 8 & 4 & 8 & 27 & 13.5 \\
\hline Pelajar & 3 & 19 & 11 & 6 & 39 & 19.5 \\
\hline \multicolumn{7}{|c|}{ Income (USD per month): } \\
\hline Below 999 & 7 & 14 & 7 & 4 & 32 & 16.0 \\
\hline $1,000-2,999$ & 10 & 18 & 11 & 17 & 56 & 28.0 \\
\hline $3,000-4,999$ & 18 & 8 & 15 & 8 & 49 & 24.5 \\
\hline $5,000-6,999$ & 5 & 5 & 10 & 5 & 25 & 12.5 \\
\hline 7,000 and above & 10 & 5 & 7 & 16 & 38 & 19.0 \\
\hline
\end{tabular}

There are four categories of tourist education background. The standard of education at degree level is the highest percentage i.e. 70.5 percent. While a total of 11.5 and 1.5 per cent have master and $\mathrm{PhD}$. Remainder (16.5 percent) only had education at certificate and diploma levels.

In terms of employment on the other hand, most of the tourists consists of professional workers, i.e. 134 people (67.0 percent). While non-professionals as many as 27 people. The rest are those who are still learning. Most of the tourists who visit Malaysia has a high source of income. A total of 28.0 percent had a source of income between 10002999 USD. Followed by the group between 3000-4999 USD that is 24.5 percent and 7,000 USD over by 19.0 percent.

\section{Exploratory Factor Analysis (EFA)}

Based on Table 3 and 4, EFA Analysis on pull and push factors started with KMO. The test results found the value of KMO more than 0.5 and Bartlett's Test of Sphericity $(\mathrm{P})$ less than 0.001 (Kaiser, 1974).

Test results for Varimax rotation on 12 items for a push factor variables found that item is divided into five (5) main groups. While the pull factors are divided into 5 groups of 24 item variables.

Total variance explained for the push and pull factors indicate that more than 50 percent of the value of each 58.4.77 and 57,649 percent. Test mean scores showed that all groups showed the scale of Mean (Average Mean) of 2.5 and above, which considered important (Salleh et al., 2011). Cronbach`s Alpha test results for all groups of factors are at the value of 0.60 and above (Hair et al., 2007).

Test mean scores showed that all groups showed the scale Mean (Average Mean) of 2.5 and above, it is considered important (Salleh et al., 2011). For the push factor for self improvement is shown cluster highest stimulus (4.048). Followed by a peace of mind (4.1230) and measuring the ability of self (3.997). For cluster social circumctances (3.646) is the lowest in the push factor.

While the pull factors indicate that the availability group have the highest motivation stimulation (3.976). Followed by attractive group is the second motivation boost (3.851). The next group of infrastructure (3.816) and the cost and transportation (3.757). For security group is the lowest stimulus attractions (3.666) but is still at a crucial stage. 
Table 3: Summary on Factors Loading, Variance Explained, The Reliability and the Average Mean of Push Factor Analysis.

\begin{tabular}{|c|c|c|c|c|c|}
\hline \multicolumn{2}{|c|}{ Factor and Items for Push Factor } & \multicolumn{4}{|c|}{ Loading Factor Explained Variance Alpha Cronbach $(\alpha)$ Average Mean } \\
\hline \multicolumn{3}{|c|}{ Self improvement: } & 27.273 & 0.652 & 4.0483 \\
\hline 1. & To enjoy themselves & 0.689 & & & \\
\hline 2. & To increase knowledge and foreign experience & 0.665 & & & \\
\hline 3. & To be free from rutine environment & 0.627 & & & \\
\hline 4. & To experience something different & 0.440 & & & \\
\hline \multicolumn{3}{|c|}{ Social Circumctances: } & 14.495 & 0.679 & 3.6463 \\
\hline 1. & To enhance social status and prestige & 0.803 & & & \\
\hline 2. & To visit family and friends & 0.726 & & & \\
\hline 3. & To be healthy & 0.685 & & & \\
\hline 4. & To socialize with family and friends & 0.540 & & & \\
\hline \multicolumn{3}{|c|}{ Peace of mind: } & 8.979 & 0.675 & 4.1233 \\
\hline 1. & To get body rest & 0.833 & & & \\
\hline 2. & To refresh mind & 0.728 & & & \\
\hline 3. & To experience on visiting famous places & 0.506 & & & \\
\hline \multicolumn{3}{|c|}{ Measuring the ability of self: } & 7.730 & 0.648 & 3.9975 \\
\hline 1. & To become traveller & 0.876 & & & \\
\hline 2. & To challenge themselves & 0.697 & & & \\
\hline
\end{tabular}

1= Very Unimportant, 5=Very Important, Kaiser-Meyer-Olkin Measure of Sampling Adequacy: 0.746, Bartlett's Test of Sphericity p< 0.000

Table 4: Summary on Factors Loading, Variance Explained, The Reliability and The Average Mean of Pull Factor Analysis.

\begin{tabular}{|c|c|c|c|c|}
\hline \multicolumn{2}{|c|}{ Factor and Items for Pull Factor } & \multicolumn{3}{|c|}{ Loading Factor Explained Variance Cronbach's Alpha (o) Average Mean } \\
\hline \multicolumn{2}{|c|}{ Availability: } & 32.548 & 0.751 & 3.9760 \\
\hline 3. & Availability of many eating out/hangout places & 0.692 & & \\
\hline 4. & Availability and variety of halal foods & 0.670 & & \\
\hline 5. & Attractive natural environment (beach, forest) & 0.604 & & \\
\hline 6. & Opportunity to visit neighboring countries & 0.586 & & \\
\hline 7. & Availability of places for praying & 0.569 & & \\
\hline \multicolumn{2}{|c|}{ Infrastructure: } & 6214 & 0.781 & 38167 \\
\hline 1. & Good telecommunication system & 0.557 & 0.181 & 3.8101 \\
\hline 2. & High quality accommodation & 0.705 & & \\
\hline 3. & Interesting sport/recreation attractions & 0.665 & & \\
\hline 4. & Variety of entertainments & 0.560 & & \\
\hline 5. & Opportunity for rest and relaxation & 0.557 & & \\
\hline 6. & Attractive tourism events/festivals & 0.550 & & \\
\hline \multicolumn{2}{|c|}{ Attractive: } & 5236 & 0785 & 38508 \\
\hline 1. & Attractive city & 0.696 & 0.185 & 3.8508 \\
\hline 2. & Interesting cultural heritage attractions & 0.637 & & \\
\hline 3. & Pleasant attitudes of the local people & 0.596 & & \\
\hline 4. & Attractive local culture and customs & 0.587 & & \\
\hline 5. & Attractive shopping & 0.492 & & \\
\hline 6. & Variety of tourist spots (for the whole family) & 0.411 & & \\
\hline \multicolumn{2}{|c|}{ Cost and Transport: } & 5019 & 0758 & 37575 \\
\hline 1. & Reasonable transportation cost & 0.766 & 0.150 & ת. \\
\hline 2. & Good ground transportation system & 0.665 & & \\
\hline 3. & Pleasant weather/climate/temperature & 0.621 & & \\
\hline 4. & Reasonable accommodation cost & 0.477 & & \\
\hline \multicolumn{2}{|c|}{ Security: } & 4.485 & 0.650 & 3.6667 \\
\hline 1. & Satisfactory level of safety and security & 0.649 & 0.050 & 3.0001 \\
\hline 2. & Good tourist information system/signage & 0.648 & & \\
\hline 3. & Satisfactory level of cleanliness & 0.548 & & \\
\hline
\end{tabular}

1= Very Unimportant, 5 = Very Important, Kaiser-Meyer-Olkin Measure of Sampling Adequacy: 0.892, Bartlett's Test of Sphericity p< 0.000 
Based on Table 5, respondents evaluate the satisfaction of products and services tourism Malaysia based on two situations, i.e. before coming to Malaysia and after the visit. They also measure customer satisfaction based on value for money. Loading factor test results found that all items variable is at level which exceed 0.40 . Test score mean shows all items satisfaction (Average Mean) is on level 2.5 and above, then it indicates that respondents feel "satisfied" on product and services offered to them.

\section{Confirmatory Factor Analysis (CFA)}

After doing the test of EFA, then test CFA started with Chisquare test Goodness of Fix (GOF). GOF test results found the test results Chi-square Goodness of Fix (GOF) value of $\chi 2(\mathrm{~N}=200, \mathrm{df}=74)=177.292 ; \mathrm{p}=0.000 ; \chi^{2} / \mathrm{df}=2.396$ and RMSEA values more than $0.80($ RMSEA $=0.084)$ have shown that the model proposed hypothesis does not match the data collected from respondents (Table 6). Then next SEM analysis should look at indicators modification indices (M.I.).

Once the Modifaction Indices (MI) carried out, test results show that the overall model measurement model was accepted that the proposed model fits the data collected with sample size. The results of Chi-square Goodness of Fix $(\mathrm{GOF})$ value of $\chi^{2}(\mathrm{~N}=200, \mathrm{df}=71)=127.577 ; \mathrm{p}=0.000$; $\chi 2 / \mathrm{df}=1.797 ; \mathrm{p}<0.05$. GFI (Goodness of fit index $)=0.915$, RMSR (Root Mean Square Residual) $=0.032$, RMSEA $($ Root Mean Square Error of Approximation $)=0.063$, AGFI (Adjusted Goodness-Of-Fit) $=0.875$, NNFI (Nonnormed Fit Index $)=0.887$, PNFI (Parsimonious Normed Fit Index) $=0.692$, CFI $($ Comparative fit index $)=0.945$, IFI
(Incremental Fit Index) $=0.946$, and RFI (Relative Fit Index $)=0.855($ Table 7$)$

\section{The assessment of the structural model}

Model of the structural cause and effect hypothesis is tested using Structural Equation Modeling (SEM). This method covers the relationship between testing each batch and factors.

First, we need to refer to the value of $\mathrm{R}^{2}$. The aim of this level of the independent variable $(\chi)$ describes the dependent variable (Y). $\mathrm{R}^{2}$ value shows 0.742 and 0.643 the number of dependent variable variance explained by the independent variables. This value represents the data are in very good condition (Henseler et al., 2009).

Next, SEM analysis results between customer satisfaction and loyalty are significant at the level of which is 0.01 . The positive effect from the tourist satisfaction loyalty travelers against Malaysia tourism products and services offered to tourists, as shown by the regression coefficient estimate standard ( $\beta$ : 0.832, t-test: $11.054 * * *)$ and predispose them to come back ( $\beta: 0.547$, t-test: $7.472 * * *)$ and recommend it to others ( $\beta$ : 0.794 , the t-test: $8.623 * * *)$. This was due to the relationship between the stimulation factor of attraction and tourist travel experience satisfaction, this is proved by the regression coefficient ( $\beta$ : 0.560 , t-test: 5.542 $* * *)$. However, it was found that the value of the coefficient of regression factors push stimulus was low to their satisfaction $(\beta: 0.228$, t-test: $1.976 * *)$ which in the model would suggest.

Table 5: Summary on Loading Factor, Variance Explained, The Reliability and Average Mean of Overall Factor Analysis.. Factor and Items for Satisfaction and Loyalty Loading FactorExplained Variance Alpha Cronbach $(\alpha)$ Average Mean Overall Tourst Satisfaction 66.893 0.751

4. Overall, Malaysia is above my expection

5. Overall, I am very satisfies with my journey in Malaysia 0.825

1=Extremely Dissatisfied" and 5=Very Satisfied",

Satisfaction:Kaiser-Meyer-Olkin Measure of Sampling Adequacy: 0.690, Bartlett's Test of Sphericity p $<0.000$

Loyalty:Kaiser-Meyer-Olkin Measure of Sampling Adequacy: 0.50, Bartlett's Test of Sphericity p $<0.000$

Table 6: Chi-square Goodness of Fix (GOF) $(\mathrm{N}=200)$

\begin{tabular}{|l|lllll|}
\hline Model & NPAR & CMIN & DF & P & CMIN/DF \\
\hline Default model & 31 & 177.292 & 74 & 0.000 & 2.396 \\
\hline
\end{tabular}

Table 7: Goodness-of-Fit Indices for the Modified Measurement Model (N=200)

\begin{tabular}{|c|c|c|c|c|c|c|c|c|c|c|}
\hline \multirow{2}{*}{ Info } & \multirow{2}{*}{$\begin{array}{l}\chi^{2} \text { Test } \\
\chi^{2}\end{array}$} & \multicolumn{3}{|c|}{ Alternative Indices } & \multicolumn{6}{|c|}{ Fit Indices } \\
\hline & & RMSEA & RMSR & CFI & GFI & AGFI & NNFI & PNFI & IFI & RFI \\
\hline Criteria & $<5.000$ & $<0.080$ & $<0.080$ & $>0.900$ & $>0.700$ & $>0.700$ & $>0.700$ & $>0.500$ & $>0.700$ & $>0.700$ \\
\hline Indicators of SEM & 2.396 & 0.063 & 0.032 & 0.945 & 0.915 & 0.875 & 0.887 & 0.692 & 0.946 & 0.855 \\
\hline
\end{tabular}

Joreskog and Sorbom (1989), Turner and Reisinger (2001) 
Therefore, travel tourist are actually influenced by the positive attraction factor and groups directly influence the loyalty of attraction travelers based on six (6) clusters, namely availability factor $(\beta$ : 0.698 , t-test: $8.850 * *)$, infrastructure $(\beta: 0.762$, t-test: $9.563 * *)$, attractive $(\beta$ : 0.801 , the t-test: $9.883 * *)$, cost and transport $(\beta: 0.753$, ttest: $9.394 * *)$ and security $(\beta$ : 0.687 , t-test: $8.840 * *)$. However, the push factors that are less tourist satisfaction is also important. Then the study must be given attention as push factors also have positive relationships as indicated by self improvement ( $\beta$ : 0.739 , t-test: $2.750 * * *)$, social circumctances ( $\beta: 0.240$, t-test: $2.952 * * *)$, peace of mind ( $\beta$ : 0.650 , t-test: $6.985 * * *)$ and measuring the ability of self $(\beta: 0.539$, t-test: $6.129 * * *)$ (Fig. 2).

\section{Conclusions and Policy Implications}

This study aims to understand the motivation, needs and requirements of tourists decide to travel. The decision will affect travel demand type required in Malaysia. Based on the results of tests on push factors motivating tourists, those who want to travel are intended to increase the confidence and the ability to measure themselves have become the main intention. These elements include aspects of language, culture and the environment. These aspects need to be addressed for every traveler. As Malaysia has a language, culture and the environment itself, these causes the selection of Malaysia as tourists from other continents. Therefore, Malaysia will need to run a promotion in the country is of potential to uncover the culture and the environment so that it can attract tourists who love to experience something different. Push factors motivating test results also reveal that travelers are considering traveling to find tranqulity. Therefore, Malaysia should offer a tourism product that can give emotional peace that allows tourists away from the routine of daily life.

Next, the test on the pull factors reveal on the availability group on having the highest motivation stimulation. One of the dimension item is natural environment. The study found that travelers need the concept of attractive natural environment such as beach and forest. Then the authorities can take the natural approach to proclaim the area for the purpose of tourism and conservation. However, this case involves the cost of maintenance and care of the environment, then the authorities can impose entrance fees to cover the cost. Meanwhile for Muslim tourists, they require the availability and variety of Halal foods and availability of places for praying. Approaches that can be taken by the authorities is to launch and promote Malaysian as a Halal tourism hub. This is because Malaysia is capable of providing the product at once it is seen attracting tourists mainly to the West Asian Muslim tourists.

Second, the tourists said that they choose destinations based on attractions such as the city, culture and history, shopping malls and society in Malaysia. Based on the item dimension, Malaysia has a wide range of tourism products to tourists. Therefore, the country should take the opportunity to promote the diversity of tourism resources, destination safe and affordable with the image of a warm and friendly locals as important tourism asset for the country to develop its tourism industry.

This study also aims to evaluate the tourist experience based on the needs and desires in making the decision to travel. Usually, tourists make a valuation based on the experience when they are in a tourist destination, either in the form of positive or negative.

Test results found that the experience of foreign tourists in Malaysia showed their positive experience of the products and services offered. The result of the experience creates loyalty in the form of repeat visits and promote the destination to friends and relatives that have the potential to make a visit. For potential travelers the source of information from the experience of other travelers are very reliable and can bring them to touristd estinations such as Malaysia.

Therefore, those who offers products and tourism services should do research and observation on the tourist perception of their products. It aims to assess the shortcomings and strengths on their products in order to improve the shortage and ensure sustainability of their enterprises. While for the Government, they can examine the findings and further disseminate experience of previous travelers to tourists who is potential in order to attract more foreign tourists to Malaysia.

Hopefully, this loyalty and satisfaction survey can be a guidance to stakeholders and policy makers in improving existing policies that can further develop national tourism industry.

Subsequent studies can be carried out in respect of climate (temperature and distribution) in the country's tourists and tourism destination. This study will review and identify factors that draw tourism climatic conditions. This study could also determine monthly tourist arrivals because of climate change on a monthly basis according to traveller's continent. 


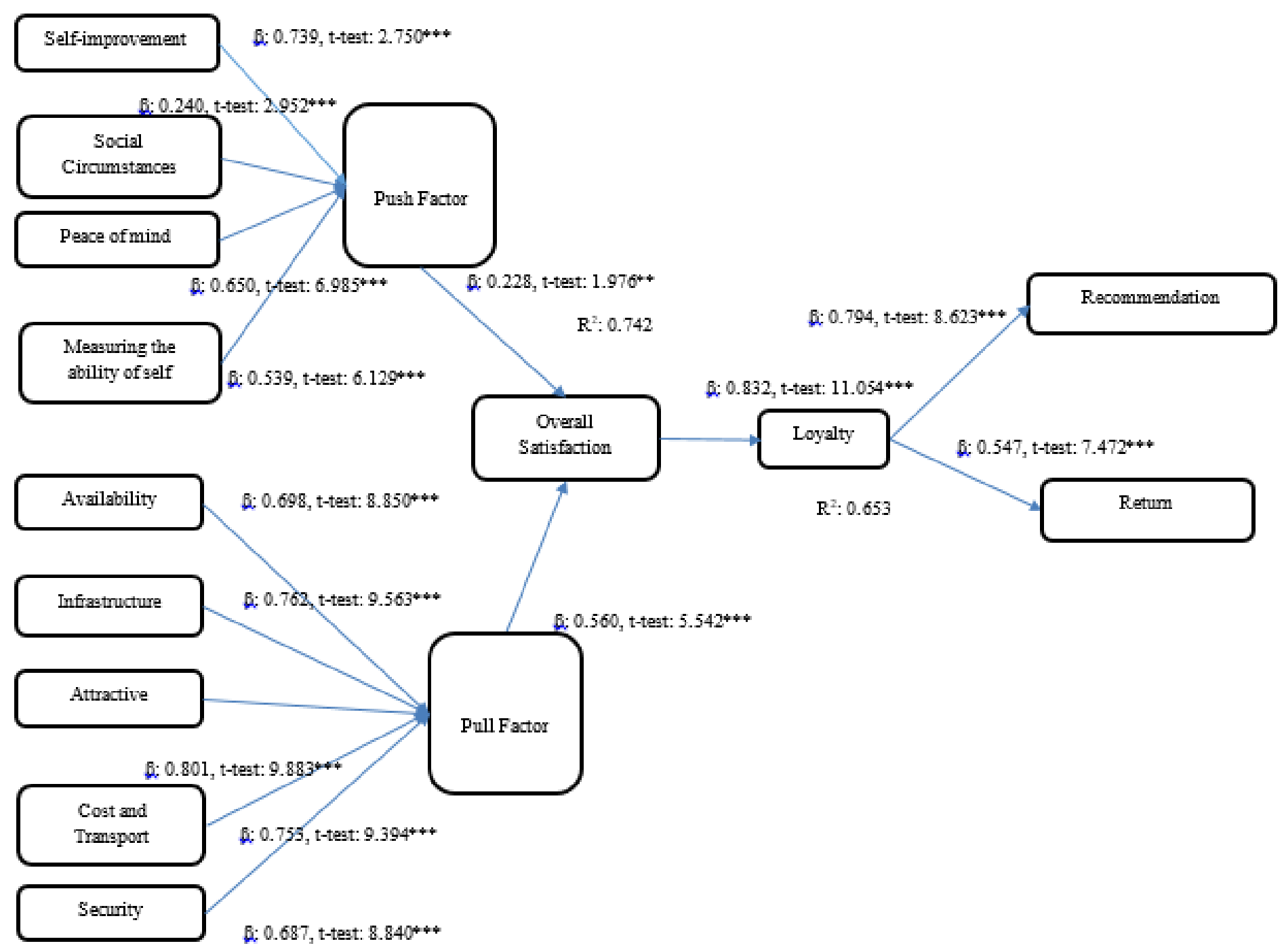

Fig. 2: Output Research Model 


\section{References}

Baniya R and Paudel K (2016) An Analysis of Push and Pull Travel Motivations of Domestic Tourists in Nepal. Journal of Management and Development Studies 27: 16-30.

Couto JPA, Batista MDGC and Botelho DR (2011) Tourists' satisfaction and loyalty in the hotel business: an application to the island of São Miguel, Azores. Working Paper Series.

Crompton, JL (1979) Motivations for pleasure vacation. Annals of tourism research 6(4): 408-424.

Dick AS and Basu K (1994) Customer loyalty: toward an integrated conceptual framework. Journal of the academy of marketing science 22(2): 99-113.

Dowell LM (2011) The Potential Impact of United States Tourists on the Cuban Market if Travel Sanctions are Lifted; as well as the Identification of their Push-Pull Travel Motivational Factors. UMASS AMHERST scholarworks.

Fishbein M and i Ajzen I (1977) Belief, Attitude, Intention, and Behaviour: An Introduction to Theory and Research. Philosophy and Rhetoric 10(2):130-132

Flavian C, Martínez E and Polo Y (2001) Loyalty to grocery stores in the Spanish market of the 1990s. Journal of Retailing and Consumer Services 8(2): 85-93.

Gremler DD and Brown SW (1996) Service loyalty: its nature, importance, and implications. Advancing service quality: A global perspective 5: 171-180.

Hair J, Money A, Page M and Samouel P (2007) Research Methods for Business. England: John Wiley and Son Ltd.

Havitz ME, Dimanche F and Bogle T (1994) Segmenting the adult fitness market using involvement profiles. Journal of Park and Recreation Administration 12(3): 38-56.

Joreskog KG and Sorbom D (1989) LISREL 7: A Guide to the Program and Applications. 2nd edition. Chicago: SPSS.

Kaiser HF (1974) An index of factorial simplicity. Psychometrika 39(1): $31-36$

Khuong MN and Ha HTT (2014) The Influences of Push and Pull Factors on the International Leisure Tourists' Return Intention to Ho Chi Minh City, Vietnam--A Mediation Analysis of Destination Satisfaction. International Journal of Trade, Economics and Finance 5(6): 490.

Kotler P and Keller KL (2009) Dirección de marketing. Pearson educación, Book.

Lam T and Hsu CHC (2006) Predicting behavioral intention of choosing a travel destination. Tourism Management 27(4): 589-599.

O'Malley L (1998) Can loyalty schemes really build loyalty?. Marketing Intelligence and Planning 16(1): 47-55.

Pesonen JA (2012) Segmentation of rural tourists: Combining push and pull motivations. Tourism and Hospitality Management 18(1): 69-82

Reihanian A, Hin TW, Kahrom E, Mahmood NB and Porshokouh $A B$ (2015) An examination of the effects of push and pull factors on Iranian national parks: Boujagh National Park, Iran. Caspian J. Env. Sci 13(3): 197-206.

Ryan C (1995) Researching tourist satisfaction: issues, concepts, problems. Routledge.

Salleh NHM, Idris SH, Shukor MS and Othman R (2013) Rangsangan motivasi ketibaan pelancong asing mengikut kawasan ke Malaysia. Jurnal Teknologi 64(1): 41-50.

Salleh NHM, Sarmidi T, Othman R, Jaafar AH and Ramli RM (2011) Satisfaction and Loyalty of Domestic Tourists towards the Kapas Island Marine Park. Journal of Tropical Marine Ecosystem 1(2): 10-21.

Shuib A, Nor M and Aziz N (1989) Analisis Permintaan Pelancongan di Malaysia. Pertanika 12(3): 425-432.

Thongma W, Leelapattana W and Hung JT (2011) Tourists'satisfaction Towards Tourism Activities Management Of Maesa Community, Pongyang SubDistrict, Maerim District, Chiang Mai Province, Thailand. Asian Tourism Management 2(1): 86-94.

Tse DK and Wilton PC (1988) Models of consumer satisfaction formation: An extension. Journal of marketing research 25(2): 204-212.

Turner WL and Reisinger Y (2001) Shopping satisfaction for domestic tourists. Journal of Retailing and Consumer Services 8(1): 15-27.

Uysal M, McGehee NG and Loker-Murphy L (1996) The Australian international pleasure travel market: Motivations from a gendered perspective. Journal of Tourism Studies 7(1): 45-57.

Valle POD, Silva JA, Mendes J and Guerreiro M (2006) Tourist satisfaction and destination loyalty intention: a structural and categorical analysis. International Journal of Business Science and Applied Management 1(1): 25-44.

Williams P and Soutar GN (2009) Value, satisfaction and behavioral intentions in an adventure tourism context. Annals of Tourism Research 36(3): 413-438.

Yiamjanya S and Wongleedee K (2014) International tourists' travel motivation by push-pull factors and the decision making for selecting Thailand as destination choice. World Academy of Science, Engineering and Technology, International Journal of Social, Behavioral, Educational, Economic, Business and Industrial Engineering 8(5): 1348-1353.

Yoon Y and Uysal M (2005) An examination of the effects of motivation and satisfaction on destination loyalty: a structural model. Tourism management 26(1): 45-56.

Yoon Y and Uysal M (2005) An examination of the effects of motivation and satisfaction on destination loyalty: a structural model. Tourism management 26(1): 45-56. 